\title{
Supporting Diversity in Early Age Children: Multicultural Competence of Early Childhood Teachers in Islamabad Pakistan
}

\author{
Ms. Fouzia Ajmal ${ }^{1}$, Dr. Masood Ahmad ${ }^{2}$ \\ Dr. Nabi Bux Jumani ${ }^{3}$, Dr. Samina Malik ${ }^{4}$
}

\begin{abstract}
Early childhood teachers need multicultural competence to prepare children for the global world. The present study was undertaken to identify the multicultural competence including i. Awareness ii. Knowledge iii. Attitude and iv. Skills of early child hood teachers working in Public schools offering one year early childhood program in Primary schools of Islamabad. The sample of the study included 95 teachers teaching Prep class in selected primary schools under Federal Directorate of Education, Islamabad. The data were collected by using an inventory on five point Likert scale in which the teachers had to mark them proficient from point 1 to 5 ( 1 being lowest) developed by researchers to measure various components of multicultural competence. On the basis of data analysis done through mean scores the teachers were categorized as novice, advanced beginner, competent, proficient and expert on all four dimensions of multicultural competence. The analysis revealed that most of the early childhood teachers were at proficient level on awareness and knowledge, competent level in attitude and at advanced beginner level in skills component of multicultural competence. There is a need to focus on and develop the multicultural competence especially attitude and skills of early childhood teachers.
\end{abstract}

Keywords: Multicultural Competence, Knowledge, Awareness, Attitude, Skills, Early Childhood Teachers

\section{Introduction}

Diversity is one of prominent features of $21^{\text {st }}$ century and its effects are on education sector also (Nair, 2014). The diversity has turned into the conspicuous component of $21^{\text {st }}$ century and this element has increased more significance because of headway of data correspondence advances (ICT) and exploratory improvements that has made the entire world a worldwide town. The influence of this element can be seen in classroom environment. At present even in one classroom there might be social differing qualities (Shizha \& Diallo, 2015). Early

\footnotetext{
${ }^{1}$ Assistant Professor, Department of Education, IIUI

Email: fouzia.ajmal@iiu.edu.pk

${ }^{2}$ Assistant Professor, Faculty of Usuluddin, IIUI

${ }^{3}$ Professor of Education, Director Directorate of Distance Education, IIUI

${ }^{4}$ Professor of Education \& Dean Faculty of Social Sciences, IIUI
} 
childhood learners are in their preoperational level and learn through concrete experience (Piaget, 1960). Every one of us understand that the requirements of early childhood kids are critical and that suitable Early Childhood Education (ECE) underpins comprehensive advancement and is a sound premise for kids to join the educational system. Shockingly, we didn't have a perceived arrangement of studies for the 3-5 year age group (Education, 2002)

Learning starts at birth. In the early years, kids learn basic abilities and create in ways that are pivotal to the achievement of their future instruction and for sure, whatever remains of their life. They figure out how to walk and develop. They figure out how to talk, gaining generally complex abilities. They learn essential intuition aptitudes, and the capacity to unite thought to dialect to activity. They create restraint and fearlessness (or a feeling of disappointment). They figure out how to identify with others and what conduct is socially worthy. They create their feeling of interest (Elkind, 1991).

A standout amongst the most problems that are begging to be addressed that families and teachers both face today is bringing up kids to be both socially skillful and touchy to their condition from a youthful age. It is crucial that youngsters figure out how to regard and acknowledge individuals whose culture and foundation vary from their own. Without executing these qualities into our youngsters, we put them in danger of growing up into grown-ups who add to the issues expedited by the segregation in the public eye. It is the duty of teachers and guardians to help get ready kids at an early age with the learning, state of mind, and aptitudes to have the capacity to exceed expectations in our unpredictable and differing world. The foundation of cultural and multicultural diversity starts at the newborn child and baby stages, it is during this time and age that children start to comprehend their identity.

Scientific findings from an assortment of fields have exhibited that support during early childhood advancement yields rich advantages not just in prompt courses for the youngster and folks, additionally after some time as far as the kid's capacity to add to the group. Interventions in the early years of a child offer a remarkable chance to keep away from or moderate learning issues, and to convey enduring advantages to people and society (Lombardi, 2009). Just having a culture-particular class or two isn't adequate to plan instructors to address the issues of the present to different kids and their families. The literature distinguished four procedures as the promising key highlights of projects that adequately address multicultural diversity. New Mexico gives a decent illustration that since the state permit requires cultural competence; early childhood instructor preparation programs utilize all courses to address decent variety in culture, dialect, financial status, and capacity. Learners require hands- 
on encounter working outside of their usual ranges of familiarity. For instance, a program in South Carolina set early youth instructors in destitute sanctuaries. Learners occupied with intelligent critical thinking and kept diaries to comprehend and stand up to their predispositions and qualities. Learners' way of life, qualities and inclinations are regularly so unobtrusive that they don't understand the effect on their conduct. To conquer such predispositions, a few projects have learners look at their family's child raising practices and formative points of reference to those of an alternate culture or ethnic gathering. Others utilize pretending practice difficulties to show application and critical thinking aptitudes (Hanson \& Lynch, 2004).

In early childhood education one of the challenging tasks for the teachers is to deal with diverse multicultural students of early age. Supporting diversity in early childhood education is necessary to help children positive feeling about themselves, their families, communities and also to develop respect and acceptance of other different people (Abdullah, 2009).

\subsection{Objectives of the Study}

The present study was undertaken to identify the multicultural competence including i. Awareness (consciousness of diversity), ii. Knowledge (understanding diversity), iii. Attitude (value of diversity) and iv. Skills (ability to deal with diversity) of early child hood teachers working in Public schools offering one year early childhood program in Primary schools of Islamabad.

\section{Review of Literature}

The objectives of Early Childhood Education (ECE) include to accommodate the all-encompassing improvement of the kid, which incorporates physical, social, enthusiastic, subjective and moral advancement, to sustain a feeling of character, to make in the kid a feeling of citizenship in group, nation and the world, to encourage a feeling of freedom, confidence and a positive mental selfportrait, to sustain resilience and regard for differing qualities, to furnish the kid with long lasting learning abilities, to give chances for dynamic learning and to give chances to self-started play, where kids arrange and survey the work they have attempted (Syed, Asif \& Yousaf, 2011). Pre-school and day care focus is advancing the social and scholarly advancement of kids. Additionally, through schedule of training, child can add to his interpersonal abilities through his communication and the specific environment (Day, 1992).

Culture alludes to the conventions, ceremonies, convictions, and values that are shared amongst a group of individuals. Every individual is a part of any society. A few families participate in different cultures. Multiculturalism refers to the sharing of numerous cultures. The essential target of a multicultural program 
is to help kids with seeing differentiations and in likenesses among all people. Allowing children to examine fluctuating societies influences open for them to see that people to have differing conventions and traditions; they every now and again share some fundamental characteristics, too. Kids find that people can be unmistakable yet still have numerous shared characteristics.

Such acknowledgement assists kids with figuring out how to recognize differences and help in limiting partialities. These acknowledgements assist kids with enduring and in regards to people from all societies and establishments. The second goal of a multicultural framework is to help pleasant social abilities. As kids make sense of how to recognize similitudes and contrasts among people, they can work with others better. They begin to see other's points of view and uniqueness. The multicultural classroom helps kids from minority societies in making cooperation and social aptitudes in a setting that may be unfamiliar to them. Their confidence is bolstered as they are seen and recognized for their uniqueness. They like themselves as different children see the estimation of their traditions and conventions. The early youth program that is socially fragile will collect the boldness of its youngsters by joining the lifestyle of the significant number of children into learning experiences ("Make your Children Multicultural !!", 2017).

The main element for a successful multicultural classroom is the instructor's knowledge of diverse cultures. It requires time to learn the backgrounds of the students and that of population nearby the school. The teachers need to instruct themselves about the convictions, qualities, sustenance, and traditions of students. In this way the teachers can share these with students so that they incorporate same in their learning experiences. Multicultural instruction is a way to deal with educating and discovering that depends on values that insist social pluralism inside socially assorted social orders in an interdependent world. Multicultural classroom deals with consensus building, regard for other cultures, and cultivating social pluralism inside racial societies. Multicultural education recognizes and joins positive racial characteristics into classroom atmosphere (Herbert \& McNergney, 1996).

Researches in multicultural education depict that multicultural strategies which emphasize holistic approaches yield better results. The consciousness of the teacher about cultural dynamics in the content, communication, and instructional method upgrades educators' capacity to design culturally enriched learning experiences (Darling-Hammond \& Bransford, 2007).

Multicultural education dimension which establish significant multicultural goals and potential results include: 1) content integration, 2) awareness of 
knowledge construction, 3) prejudice reduction, 4) improved teaching method, and 5) an empowering school culture (Banks, 2009).

Instructors who have been personally involved in multicultural education have recognized a few advantages of the global perspective of multicultural instruction. Some of these long term advantages are:

a. Multicultural training builds productivity in light of the fact that a variety of mental resources are accessible for finishing the same tasks and it advances subjective and moral development among all individuals.

b. Multicultural education increases critical thinking abilities through the alternate points of view connected to same issues to reach solutions.

c. Multicultural training builds positive connections through accomplishment of basic objectives, admiration, gratefulness.

d. Multicultural education decreases stereotyping and prejudice through direct contact and associations among diverse individuals.

e. Multicultural education helps to build a more extensive and more refined perspective of the world (Cumming-McCann, 2003).

\section{Research Methodology}

It was a descriptive study. Survey method was used to collect data.

\subsection{Sample of Study}

The sample of the study included 95 teachers teaching Prep class in selected primary schools under Federal Directorate of Education, Islamabad. Islamabad is the capital city of Pakistan, having population from all over the country and some other nations as well multiculturalism is seen more as compared to other areas.

\subsection{Instrumentation}

The data were collected by using an inventory on five point Likert scale in which the teachers had to mark them proficient from point 1 to 5 ( 1 being lowest) developed by researchers to measure various components of multicultural competence of early childhood teachers. The scale comprised on four dimensions of multicultural competence including 8 items on the awareness (consciousness of diversity), 15 items on knowledge (understanding diversity), 06 items on attitude (value of diversity) and 08 items on skills (ability to deal with diversity). It was a self-reported scale mean the teachers had to rate themselves on various items related to components of multicultural diversity and skills required to handle it. So the minimum and maximum scores can be as follows: 
Table 1 Minimum and Maximum scores of Multicultural Competence

\begin{tabular}{lcc}
\hline Sub Scale & Minimum Score & Maximum Score \\
Awareness & 8 & 40 \\
Knowledge & 15 & 75 \\
Attitude & 6 & 30 \\
Skills & 8 & 40
\end{tabular}

The data analysis was done through mean scores. The Early Childhood Teachers were categorized as novice, advanced beginner, competent, proficient and expert on all four dimensions of multicultural competence on the basis of mean scores as follows:

Table 2 Levels of Multicultural Competence

\begin{tabular}{llllll}
\hline Sub Scale & Novice & $\begin{array}{l}\text { Advanced } \\
\text { Beginner }\end{array}$ & Competent & Proficient & Expert \\
Awareness & 8 & $9-16$ & $17-24$ & $25-32$ & $33-40$ \\
Knowledge & 15 & $16-30$ & $31-45$ & $46-60$ & $61-75$ \\
Attitude & 6 & $7-12$ & $13-18$ & $19-24$ & $25-30$ \\
Skills & 8 & $9-16$ & $17-24$ & $25-32$ & $33-40$ \\
\hline
\end{tabular}

\section{Data Analysis \& Results}

The data analysis depicted the following scores of early childhood teachers regarding the multicultural competence:

Table 3 Levels of Multicultural Competence of ECE Teachers

\begin{tabular}{lcc}
\hline Sub Scale & Mean Score & Level \\
\hline Awareness & 26.4 & Proficient \\
Knowledge & 47.6 & Proficient \\
Attitude & 16.7 & Competent \\
Skills & 15.3 & Advanced Beginner \\
\hline $\mathrm{N}=95$ & &
\end{tabular}

The Table 3 shows the level of competence of ECE teachers in selected public schools of Islamabad. It is evident that the mean score of awareness is $26.4 / 40$ and it comes in proficient range, the mean score of knowledge is 47.6/75 and is also in range of proficient. The mean score on category attitude is $16.7 / 30$ which is in range of competent and needs to be worked out. The skills which is most important component of teaching at any level is weak as the score 15.3/40 on skills of multicultural competence comes in the range of advance beginner. The analysis revealed that most of the early childhood teachers were at proficient level on awareness and knowledge, competent level in attitude and at advanced beginner level in skills component of multicultural competence. 


\section{Discussion}

The analysis revealed that most of the early childhood teachers were at proficient level on awareness and knowledge and other study states that the consciousness of the teacher about cultural dynamics in the content, communication, and instructional method upgrades educators' capacity to design culturally enriched learning experiences (Darling-Hammond \& Bransford, 2007). They are at competent level in attitude and at advanced beginner level in skills component of multicultural competence.

A standout amongst the problems that need to be addressed that families and instructors both face today is bringing up youngsters to be both socially equipped and sensitive to their surroundings from their early age. Additionally, through schedule of training child can add to his interpersonal abilities through his communication and the specific environment (Day, 1992). It is the obligation of teachers and parents to get ready children at an early age with the learning, state of mind, and aptitudes to have the capacity to meet expectations in our perplexing and different world. So, the teachers need to be more competent in this regard and need to develop the required skills among themselves first in order to develop these competencies in their students as multicultural education helps to build a more extensive and more refined perspective of the world (Cumming-McCann, 2003).

\section{Recommendations}

There is a need to focus on and develop the multicultural competence especially attitude and skills of early childhood teachers to enable them to support diversity in the early years classrooms. These skills may be practiced in the pre-service and in-service training of teachers and mentoring may be provided for developing the multicultural competence of early childhood teachers. As evident from the researches that the multicultural competences are important for the early childhood teachers and it has to be focused in pre service and in-service teacher education programs not by a few lectures, but integrating it as essential component of those programs. The management of early childhood education may work on this aspect of the teachers also.

It is also imperative that children learn how to regard and acknowledge individuals whose society and foundations vary from their own. Without executing these qualities into our kids, we put them at danger of growing up into grown-ups who add to the issues brought on by the discrimination in the society. 


\section{References}

Abdullah, A. C. (2009). Multicultural education in early childhood: Issues and challenges. Journal of International Cooperation in Education, 12(1), 159-175.

Banks, J. A. (Ed.). (2009). The Routledge international companion to multicultural education. Routledge.

Cumming-McCann, A. (2003). Multicultural education: Connecting theory to practice. Focus on Basics: Connecting research and practice, 6, 9-12.

Darling-Hammond, L., \& Bransford, J. (2007). Preparing teachers for a changing world: What teachers should learn and be able to do. John Wiley \& Sons.

Day, B. (1992). The Education and Care of Young Children. Report of the ASCD Early Childhood Consortium. Association for Supervision and Curriculum Development, Alexandria, Va.

Education, E. C. (2002). National Curriculum. ASER Pakistan.

Elkind, D. (1991). Perspectives on Early Childhood Education: Growing with Young Children toward the $21^{\text {st }}$ Century. NEA Early Childhood Education Series. NEA Professional Library.

Hanson, M. J., \& Lynch, E. W. (2004). Understanding families: Approaches to Diversity, Disability, and Risk. US: Paul H Brookes Publishing.

Herbert, J. M., \& McNergney, R. F. (1996). The Case of Deming, New Mexico: International Public Education. Multicultural Videocase Series. Washington, DC: AACTE Publications.

Make your Children Multicultural (2017).!!. Retrieved from http://gdgoenkaworldschool.blogspot.com/2012/10/make-your-childrenmulticultural.html

Lombardi, J. (2009). Time to care: Redesigning child care to promote education, support families, and build communities. Temple University Press. 
Nair, U. (2014). Instructional Design Models in the $21^{\text {st }}$ Century: A Review. EdTech Review, March.

Piaget, J. (1960), The child's conception of the world. London: Routledge.

Shizha, E., \& Diallo, L. (2015). Africa in the Age of Globalization: Perceptions, Misperceptions and Realities. Ashgate Publishing, Ltd.

Syed, S. Z., Asif, M., \& Yousaf, A. (2011). Rethinking ECE in Pakistan. Journal of Elementary Education, 21(2), 65-76. 